\title{
Clonal micropropagation of Thymus vulgaris $\mathrm{L}$.
}

\author{
$A$ Sh Tevfik ${ }^{1, *}$, and $N A$ Yegorova $^{1}$ \\ ${ }^{1}$ Research Institute of Agriculture of Crimea, 295493, Kievskaya str.150, Simferopol, Russian \\ Federation
}

\begin{abstract}
Thymus vulgaris L. is one of the widely known spicy aromatic and medicinal plants. Thyme plant material is widely used in medicine, cooking and perfumery. To increase the efficiency of breeding and seed production, it is necessary to develop biotechnological techniques, in particular, clonal micropropagation. The aim of the research is to optimize the composition of culture media for the main stages of propagation in vitro and to select adaptation ex vitro conditions for the development of Thymus vulgaris. clonal micropropagation. The article presents the results of studies of explant morphometric parameters cultivated on 20 variants of culture media at firstsecond stages of micropropagation. It was found that the optimal culture medium at the introduction stage is MS medium with $1.0 \mathrm{mg} / \mathrm{l} \mathrm{Kin}$ and 1.0 $\mathrm{mg} / \mathrm{l} \mathrm{GA3}$, on which, on average, 2.2 microshoots per explant with a length of $1.9 \mathrm{~cm}$ were obtained. Both high vitrification rate of microshoots and formation of small shoots $(0.6-0.9 \mathrm{~cm})$ were observed on media supplemented with BAP or TDZ. The most effective culture medium at the proper propagation stage is MS with $1.0 \mathrm{mg} / \mathrm{l} \mathrm{Kin}$, on which 4.6 shoots per explant and the multiplication index 12.8 were obtained. It is advisable to root microshoots at the 3rd stage of micropropagation on MS culture medium supplemented with $1.0 \mathrm{mg} / 1 \mathrm{IBA}$ or $1.0 \mathrm{mg} / \mathrm{l} \mathrm{IAA}$. It has been shown that it is possible to obtain high plant survival rate $(89.5 \%)$ during adaptation ex vitro, using a substrate consisting of peat and perlite (1:1).
\end{abstract}

\section{Introduction}

Thymus is a perennial shrub of the Lamiaceae family with a high content of biologically active substances. Thyme essential oil and plant material are part of numerous combined medicines that have a beneficial effect on the body. They strengthen immunity, positively affect the nervous system and the activity of the gastrointestinal tract. Thyme has analgesic, expectorant, antispasmodic, anthelmintic, antipruritic and antioxidant effects. The most important components of thyme essential oil are thymol and linalool. Thymol is of particular value due to its antiseptic, bactericidal and disinfectant properties. There is evidence of its use against antibiotic-resistant body microflora [1-2].

The studies concerning the creation of new highly productive cultivars of thyme are carried out in the FSBSI "Research Institute of Agriculture of Crimea". To increase the efficiency of breeding and seed production, it is necessary to use biotechnological methods.

* Corresponding author: tevfik.arzy@ yandex.ru 
They are necessary for the accelerated propagation of valuable samples, which will significantly increase the multiplication index, accelerate the breeding process, help to obtain healthy planting material, as well as propagate plants that are difficultly propagated by traditional methods, create genebanks of valuable genotypes in vitro, etc. When analyzing publications on the study of thyme in vitro, it should be noted that they all relate to species unfound in Russia (T. mastichina, T. hyemalis, T. broussonetii, T. moroderi, $T$. bleicherianus, T. syriacus, T. fruticosus, T. majorana, T. capitatus, T. persicus). There are no clear and effective methods of clonal micropropagation for most Thyme species. During micropropagation of thyme, researchers often faced such problems as a high frequency of explant contamination, explant darkening due to a high concentration of phenolic compounds inhibiting their development in vitro [3-4], low survival rate or shoot vitrification [5-6], low multiplication index. Only a few scientific works were devoted to studying the features of the morphogenetic potential of $T$. vulgaris in vitro [7]. Our study aimed to optimize the composition of the culture medium for the main stages of propagation in vitro and to select adaptation ex vitro conditions for the development of a technique for clonal micropropagation of Thymus vulgaris $\mathrm{L}$.

\section{Materials and methods}

The tissues and organs of Thymus vulgaris L. (breeding sample No. 20841) from the collection of the FSBSI "Crimean Scientific Research Institute of Agriculture" served as the material for research. Stem segments with one node $(8-10 \mathrm{~mm})$ were introduced into the culture in vitro. Explants were cultured on various modifications of the Murashige and Skoog (MS) culture media supplemented with gibberellic acid $\left(\mathrm{GA}_{3}\right)$, kinetin (Kin), 6benzylaminopurine (BAP), $\beta$-indolyl-3-butyric acid (IBA) and $\beta$-indolyl-3-acidic acid (IAA) (Sigma, USA). Hormone-free MS culture medium (HF) was used as a control. Cultivation at different stages of propagation was carried in test tubes $(16 \times 150 \mathrm{~mm})$ or glass jars $(250 \mathrm{ml})$ closed with foil. In tubes with $10 \mathrm{ml}$ of culture medium (at the introduction stage), one explant was placed; in jars with $30 \mathrm{ml}$ of medium (second third stages of micropropagation) - three or four explants. Cultivation was carried out at $24-26^{\circ} \mathrm{C}, 70 \%$ relative humidity, 16 hours of photoperiod with light intensity of 2000 3000 lux. The duration of the cultivation: at the introduction stage -40 days, at the stage of micropropagation or rooting - 70 days, adaptation ex vitro - 60 days. When analyzing the cultures, the number of shoots (pcs./explant), their length $(\mathrm{cm})$, number of nodes (pcs./shoot), frequency of shoots vitrification (\%), frequency of rhizogenesis (\%), as well as number (pcs./shoot) and length $(\mathrm{cm})$ of roots were determined.

The multiplication index was calculated as the number of microshoots that can be obtained in one subculture. For this, the number of shoots formed on the explant was multiplied by the number of nodes on the shoot. $50-100 \mathrm{~mm}$ long microshoots with a welldeveloped root system were used for adaptation ex vitro. Plants were planted in $200 \mathrm{ml}$ plastic cups with a sterile substrate and cultivated at $24 \pm 2{ }^{\circ} \mathrm{C}$ and relative humidity 75 $85 \%$. The components of the substrate - peat, perlite and soil. In each experiment, at least 20 explants were analyzed. The experiment was repeated three times. Statistical data processing and analysis were performed using Microsoft Office software package (Excel 2010). The significance of differences was calculated by Student t-test at $\mathrm{P} \leq 0.05$. The tables show the average values and their standard errors; the graphs present the average values and confidence intervals. 


\section{Results}

After two to three weeks, we observed the development of axillary shoots, as well as the induction of adventitious buds and shoots when explants were introduced in vitro. The effect of three cytokinins (BAP, TDZ and Kin) after their introduction into the culture medium together with IAA, IBA and $\mathrm{GA}_{3}$ was analyzed. The types and concentrations of growth regulators studied in the work were chosen based on our preliminary studies [5]. When using MS culture media containing TDZ, explants began to develop on the 25th 28th day after introduction; on media containing Kin and BAP - on the 8th -15 th day. Callus formation was noted on the following culture media: $\mathrm{MS}+\mathrm{Kin}(1.0 \mathrm{mg} / \mathrm{l})+\mathrm{GA}_{3}$ $(1.0 \mathrm{mg} / \mathrm{l})+\mathrm{BAP}(1.0 \mathrm{mg} / \mathrm{l})$ or $\mathrm{MS}+\mathrm{Kin}(1.0 \mathrm{mg} / \mathrm{l})+\mathrm{GA}_{3}(1.0 \mathrm{mg} / \mathrm{l})+\mathrm{IAA}(0.5 \mathrm{mg} / \mathrm{l})$. Root formation was observed on hormone-free MS medium or MS + Kin $(1.0 \mathrm{mg} / \mathrm{l})+\mathrm{GA}_{3}$ $(1.0 \mathrm{mg} / \mathrm{l})$.

The maximum number of shoots per explant (3.1-3.4 pcs.) was detected on media supplemented with BAP or TDZ (Fig. 1). However, the use of these cytokinins caused microshoots vitrification. At the same time, the shoots were yellow-green, their internodes were shortened, as well as the length was up to $0.9 \mathrm{~cm}$ (Fig. 2). So, we could not use them for further microcutting.

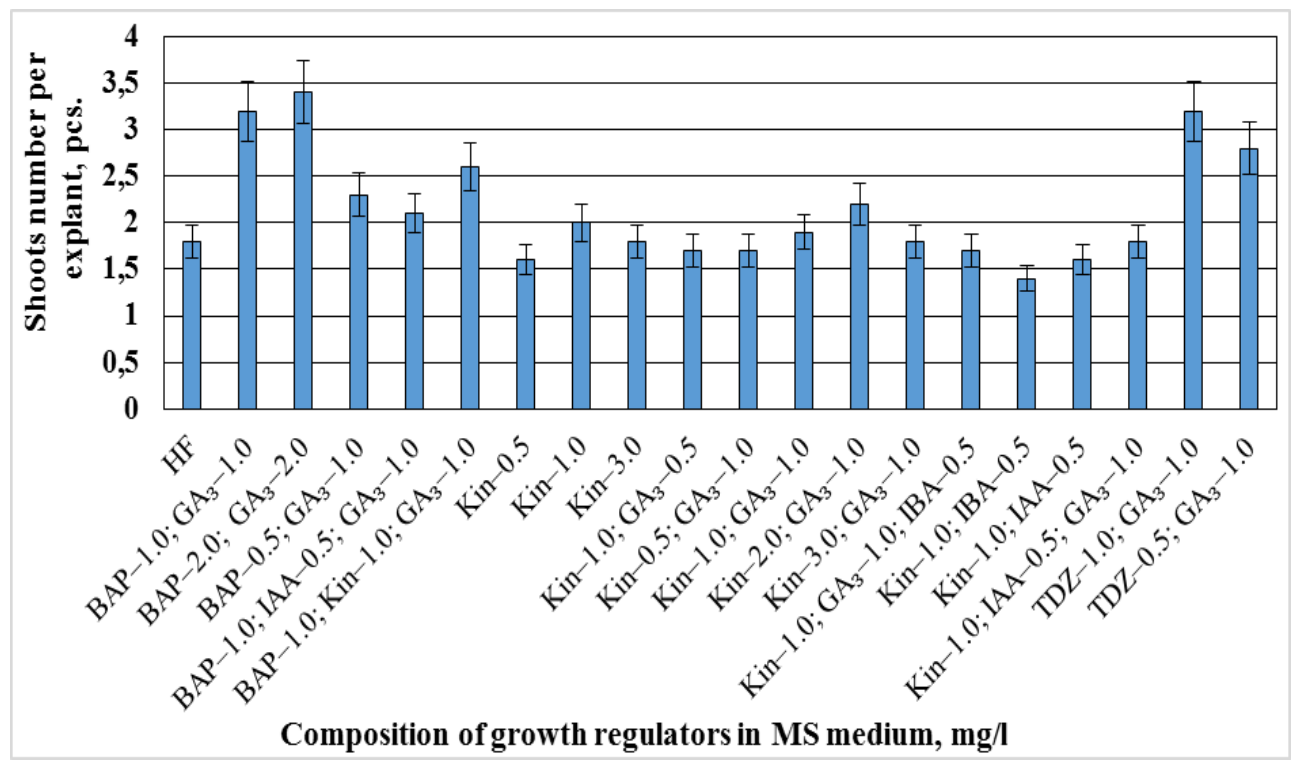

Fig. 1. The influence of the culture medium composition on shoots number per explant at the first stage of thyme clonal micropropagation. 


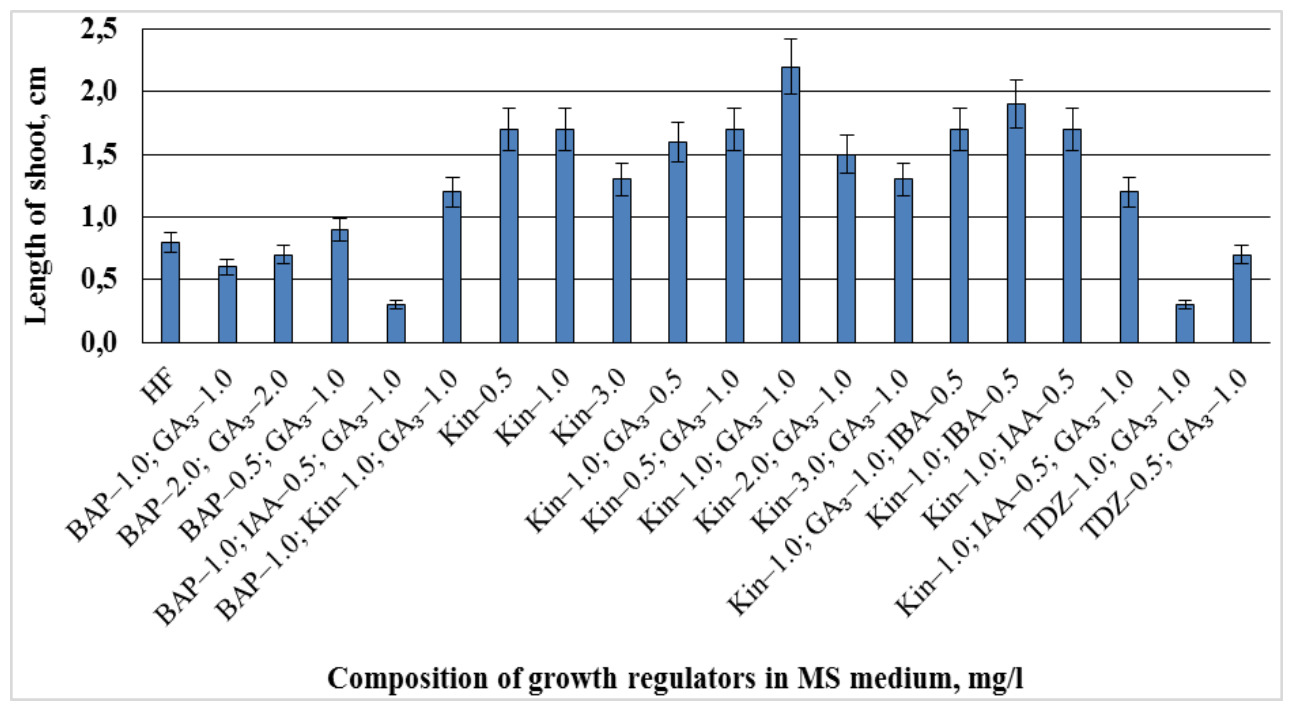

Fig. 2. The influence of the culture medium composition on shoot length at the first stage of thyme clonal micropropagation.

Dark green microshoots $1.5-1.8 \mathrm{~cm}$ long developed when cultivated on culture media containing kinetin as cytokinin. A decrease in microshoots length $(1.3 \mathrm{~cm})$ on culture medium with a higher kinetin concentration $(3.0 \mathrm{mg} / \mathrm{l})$ was noted. Therefore, for better development of explants at the introduction stage and subsequent propagation, MS culture medium containing $1.0 \mathrm{mg} / \mathrm{K} \mathrm{Kin}$ and $1.0 \mathrm{mg} / 1 \mathrm{GA}_{3}$ is necessary. Using this medium, we obtained 1.9 shoots/explant of $2.3 \mathrm{~cm}$ long.

Microcuttings of shoots obtained by in vitro introduction was carried out for further propagation. At the stage of proper micropropagation, microcuttings with one node were used as explants.

In previous studies, we had demonstrated that at the second stage of $T$. vulgaris clonal micropropagation, the maximum multiplication index was when glass jars were used as culture vessels and the duration of the cultivation cycle was 70 days. [6]. Therefore, in this study, we used similar cultivation modes.

It was found that the type of cytokinin had a significant effect at the second stage of micropropagation. The use of various cytokinins caused different morphogenetic reactions of the explants. BAP or TDZ (together with $\mathrm{GA}_{3}$ ) stimulated adventitious shoot formation at the bottom of the explants (Table 1). However, the obtained microshoots (4.3-6.5 pcs./explant) were shortened $(0.6-0.9 \mathrm{~cm}$ long). The culture medium containing only BAP or TDZ as hormones did not contribute to the formation of numerous shoots per explant (1.1 pcs.). This indicates that these cytokinins caused multiple shoot formation only when combined with $\mathrm{GA}_{3}$. 
Table 1. The influence of the culture medium composition on the explant development at the second stage of thyme clonal micropropagation.

\begin{tabular}{|c|c|c|c|c|c|}
\hline $\begin{array}{l}\text { Growth regulators in } \\
\text { MS culture medium, } \mathrm{mg} / \mathrm{l}\end{array}$ & $\begin{array}{c}\text { Shoots } \\
\text { number per } \\
\text { explant, pcs. }\end{array}$ & $\begin{array}{c}\text { Nodes } \\
\text { number per } \\
\text { shoot, pcs. }\end{array}$ & $\begin{array}{c}\text { Shoot } \\
\text { length, } \\
\mathrm{cm}\end{array}$ & \begin{tabular}{|c|} 
Roots \\
number per \\
explant, \\
pcs. \\
\end{tabular} & $\begin{array}{l}\text { Multiplication } \\
\text { index }\end{array}$ \\
\hline $\mathrm{HF}$ & $4.2 \pm 0.5$ & $2.9 \pm 0.1$ & $2.5 \pm 0.1$ & $2.3 \pm 0.1$ & $10.5 \pm 1.3$ \\
\hline Kin -0.5 & $4.5 \pm 0.5$ & $3.3 \pm 0.2$ & $2.6 \pm 0.2$ & $2.9 \pm 0.3$ & $11.7 \pm 1.4$ \\
\hline Kin -1.0 & $4.6 \pm 0.8$ & $2.8 \pm 0.2$ & $2.8 \pm 0.1$ & $4.9 \pm 0.3$ & $12.8 \pm 1.9$ \\
\hline Kin $-1.0 ; \mathrm{GA}_{3}-1.0$ & $3.5 \pm 0.5$ & $1.9 \pm 0.3$ & $2.7 \pm 0.2$ & $4.4 \pm 0.6$ & $7.5 \pm 0.9$ \\
\hline $\begin{array}{c}\text { Kin }-1.0 ; \mathrm{GA}_{3}-1.0 ; \mathrm{IAA}- \\
0.5\end{array}$ & $3.5 \pm 0.4$ & $1.5 \pm 0.2$ & $2.5 \pm 0.2$ & $4.3 \pm 0.4$ & $5.7 \pm 0.7$ \\
\hline Kin $-1.0 ;$ IAA -0.5 & $4.5 \pm 0.7$ & $2.8 \pm 0.2$ & $2.4 \pm 0.2$ & $4.1 \pm 0.5$ & $10.7 \pm 1.7$ \\
\hline $\begin{array}{c}\text { Kin }-1.0 ; \mathrm{GA}_{3}-1.0 ; \mathrm{IBA}- \\
0.5\end{array}$ & $3.4 \pm 0.6$ & $3.3 \pm 0.4$ & $2.9 \pm 0.3$ & $3.9 \pm 0.4$ & $12.7 \pm 1.5$ \\
\hline Kin $-1.0 ;$ IBA -0.5 & $4.1 \pm 0.1$ & $2.8 \pm 0.2$ & $2.7 \pm 0.1$ & $4.0 \pm 0.4$ & $10.2 \pm 1.6$ \\
\hline $\mathrm{Kin}-0.5 ; \mathrm{GA}_{3}-0.5$ & $4.6 \pm 0.5$ & $3.4 \pm 0.4$ & $2.5 \pm 0.3$ & $4.0 \pm 0.5$ & $11.5 \pm 1.5$ \\
\hline Kin - 1.0; IAA - 0.2 & $4.6 \pm 0.5$ & $3.5 \pm 0.2$ & $2.6 \pm 0.1$ & $4.0 \pm 0.4$ & $12.0 \pm 1.6$ \\
\hline $\begin{array}{c}\mathrm{Kin}-1.0 ; \mathrm{GA}_{3}-1.0 ; \mathrm{BAP}- \\
0.2 \\
\end{array}$ & $6.7 \pm 0.1$ & $0.7 \pm 0.1$ & $1.1 \pm 0.1$ & $2.0 \pm 0.1$ & $8.0 \pm 0.9$ \\
\hline $\mathrm{BAP}-0.5$ & $1.1 \pm 0.1$ & $1.0 \pm 0.1$ & $2.6 \pm 0.2$ & 0 & $2.9 \pm 0.2$ \\
\hline $\mathrm{BAP}-1.0$ & $1.1 \pm 0.1$ & $1.1 \pm 0.1$ & $2.2 \pm 0.2$ & 0 & $2.4 \pm 0.2$ \\
\hline $\mathrm{BAP}-0.5 ; \mathrm{GA}_{3}-2.0$ & $6.5 \pm 0.5$ & $0.9 \pm 0.1$ & $1.1 \pm 0.1$ & $1.1 \pm 0.1$ & $7.2 \pm 0.8$ \\
\hline $\mathrm{BAP}-0.5 ; \mathrm{GA}_{3}-1.0$ & $4.6 \pm 0.5$ & $0.7 \pm 0.1$ & $1.1 \pm 0.1$ & $1.1 \pm 0.1$ & $5.1 \pm 0.6$ \\
\hline $\begin{array}{c}\mathrm{BAP}-0.5 ; \mathrm{GA}_{3}-2.0 ; \mathrm{IBA}- \\
0.5 \\
\end{array}$ & $4.3 \pm 0.4$ & $0.6 \pm 0.1$ & $1.1 \pm 0.1$ & $1.1 \pm 0.1$ & $4.7 \pm 0.3$ \\
\hline $\mathrm{BAP}-0.5 ; \mathrm{IAA}-0.5$ & $1.6 \pm 0,1$ & $1.3 \pm 0.2$ & $2.5 \pm 0.3$ & $1.1 \pm 0.1$ & $4.0 \pm 0.3$ \\
\hline $\mathrm{TDZ}-0.5$ & $1.1 \pm 0.2$ & $1.8 \pm 0.2$ & $1.8 \pm 0.2$ & 0 & $2.0 \pm 0.2$ \\
\hline TDZ -1.0 & $1.1 \pm 0.2$ & $1.7 \pm 0.2$ & $1.7 \pm 0.2$ & 0 & $1.9 \pm 0.2$ \\
\hline $\mathrm{TDZ}-1.0 ; \mathrm{GA}_{3}-1.0$ & $2.1 \pm 0.2$ & $2.7 \pm 0.4$ & $1.9 \pm 0.3$ & 0 & $5.7 \pm 0.4$ \\
\hline $\mathrm{TDZ}-2.0 ; \mathrm{GA}_{3}-1.0$ & $3.3 \pm 0.3$ & $1.5 \pm 0.2$ & $0.7 \pm 0.1$ & 0 & $5.0 \pm 0.5$ \\
\hline
\end{tabular}

The combined use of BAP and Kin also induced the formation of many small shoots at the base of the explants. The use of kinetin alone as cytokinin contributed to a significant increase of explant length $(2.4-2.9 \mathrm{~cm})$. In this case, the shoot formation of the first and second order was noted. Combining two methods of propagation: multiple shoot formation and microcutting made it possible to increase the multiplication index significantly. The addition of auxins and $\mathrm{GA}_{3}$ to kinetin caused a decrease in the multiplication index on most culture media. Therefore, it is necessary to use MS culture medium containing $1.0 \mathrm{mg} / \mathrm{l} \mathrm{Kin}$ for the better development of explants and subsequent micropropagation at the second stage.

At the second stage of micropropagation, on media with kinetin, in addition to multiple shoots, root formation with a frequency of 7.1-98.0\% was noted. However, the number of roots formed on most culture media containing only cytokinin was low (2.2-4.9 pcs./shoot). It should be noted that the use of even a low concentration of TDZ or BAP $(0.2-0.5 \mathrm{mg} / \mathrm{l})$ inhibited the process of rhizogenesis; the formation of roots was observed only on single microshoots. Therefore, for active root formation of microshoots, it is advisable to transfer them to media containing auxins. At the third stage of micropropagation (in vitro rooting), it was found that when using a hormone-free culture medium, the number of roots did not exceed 2.7 pcs./shoot (Fig. 3). Herewith, the use of culture medium MS with $1.0 \mathrm{mg} / 1 \mathrm{IBA}$ increased this indicator by 2.8 times; MS with $1.0 \mathrm{mg} / 1 \mathrm{IAA}$ - by 2.4 times; MS with 1.0 
mg/l NAA - by 2.3 times compared to the medium without growth regulators. The use of culture media with auxins increased the frequency of root formation (63.3-98.3\%) compared with the medium without growth regulators $(33.4 \%)$. The largest average root length $(2.6 \mathrm{~cm})$ was obtained when cultivating on MS medium with $1.0 \mathrm{mg} / \mathrm{lBA}$.

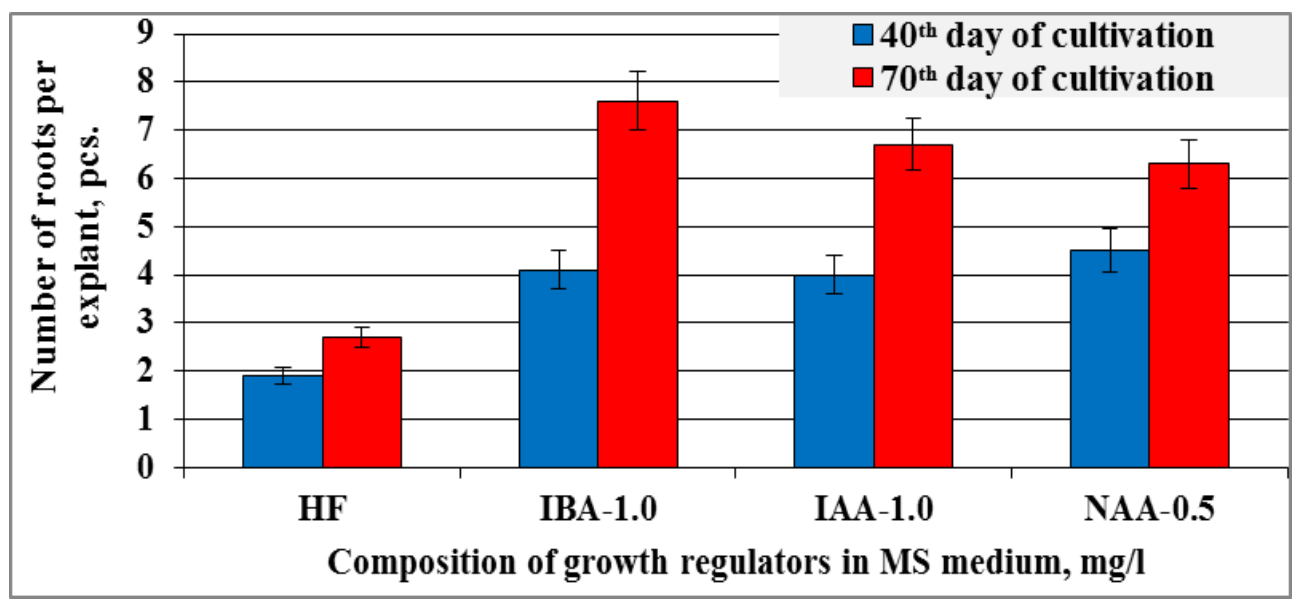

Fig. 3. The effect of culture medium composition on the number of roots per explant at the third stage of thyme clonal micropropagation.

It should be noted that the duration of cultivation also influenced the process of root formation. Thus, on the 70th day on media with auxins, the number of roots increased by 1.4-1.9 times compared to the cultivation during 40 days.

Therefore, for active root formation of thyme microshoots, it is necessary to cultivate them for 70 days on MS culture medium with $1.0 \mathrm{mg} / 1 \mathrm{IBA}$. Under these conditions, an average of 7.7 roots per shoot were formed.

The final stage of clonal micropropagation is ex vitro adaptation of microplants. The effect of the substrate on the survival rate of rooted plants in vitro for optimizing the adaptation conditions was studied (Table 2). It was revealed that plant survival was high in all studied substrates (80.2-93.5\%). When growing plants in peat, more shoots per regenerant was formed compared to perlite ( $12.7 \mathrm{pcs}$. and $8.1 \mathrm{pcs}$., respectively). The use of perlite and peat for adaptation contributed to the production of bright green plants with well-developed stems and leaves.

Table 2. The effect of the substrate type on the development of thyme microplants during adaptation ex vitro.

\begin{tabular}{|c|c|c|c|c|c|c|}
\hline Substrate type & $\begin{array}{c}\text { Survival } \\
\text { rate, \% }\end{array}$ & $\begin{array}{c}\text { Number of shoots } \\
\text { per regenerant, } \\
\text { pcs. }\end{array}$ & $\begin{array}{c}\text { Shoot } \\
\text { length, cm }\end{array}$ & $\begin{array}{c}\text { Total } \\
\text { weight, } \\
\text { g. }\end{array}$ & $\begin{array}{c}\text { Weight of } \\
\text { raw } \\
\text { materials, g. }\end{array}$ & $\begin{array}{c}\text { Weight of } \\
\text { roots, g. }\end{array}$ \\
\hline Peat & $90.3 \pm 10.4$ & $12.7 \pm 1.4$ & $7.9 \pm 0.3$ & $1.5 \pm 0.2$ & $1.3 \pm 0.2$ & $0.10 \pm 0.02$ \\
\hline Peat + perlite $(1: 1)$ & $89.5 \pm 9.5$ & $11.9 \pm 1.6$ & $9.6 \pm 0.3$ & $2.4 \pm 0.3$ & $2.1 \pm 0.3$ & $0.34 \pm 0.06$ \\
\hline $\begin{array}{c}\text { Peat + perlite + soil } \\
(1: 1: 1)\end{array}$ & $82.6 \pm 9.3$ & $9.2 \pm 1.0$ & $9.3 \pm 0.3$ & $1.4 \pm 0.1$ & $1.3 \pm 0.1$ & $0.10 \pm 0.01$ \\
\hline Soil + perlite (1:1) & $80.2 \pm 9.2$ & $8.4 \pm 0.7$ & $6.0 \pm 0.2$ & $1.0 \pm 0.1$ & $0.8 \pm 0.1$ & $0.21 \pm 0.04$ \\
\hline Perlite & $93.5 \pm 9.8$ & $8.1 \pm 0.9$ & $5.6 \pm 0.3$ & $0.8 \pm 0.1$ & $0.5 \pm 0.1$ & $0.22 \pm 0.03$ \\
\hline
\end{tabular}

In the course of the research, the maximum shoot length $(9.3-9.6 \mathrm{~cm})$ was obtained using peat and perlite (1:1) or peat, perlite and soil (1:1:1). Adaptation of microcutting in perlite or a mixture of soil and perlite reduced this indicator. The acclimatization of plants in a substrate consisting of peat and perlite contributed to an increase in the total weight of 
established regenerants by 1.6-3.0 times compared to other types of substrate. This was due to a significant increase in the aboveground mass of microshoots.

\section{Discussion}

In our study, we found that $T$. vulgaris requires four traditional stages of clonal micropropagation: introduction in vitro, micropropagation, rhizogenesis in vitro, adaptation ex vitro. Optimal cultivation conditions for each stage of micropropagation were selected. A comparative analysis of the effect of three cytokinins on the explant development at the first stage of clonal micropropagation was carried out. It was revealed that BAP or TDZ together with $\mathrm{GA}_{3}$ stimulated formation of a larger number of microshoots (2.2-3.4 pcs./explant) compared to Kin (1.6-2.2). The use of culture media with Kin made it possible to obtain 1.3-1.8 cm long microshoots; with BAP or TDZ $-0.9 \mathrm{~cm}$ long. The optimal MS culture medium for the explants introduction in vitro contains $1.0 \mathrm{mg} / \mathrm{l} \mathrm{Kin}$ and $1.0 \mathrm{mg} / \mathrm{l}$ $\mathrm{GA}_{3}$. We obtained 2.2 shoots per explant $1.9 \mathrm{~cm}$ long on this medium. However, an analysis of scientific publications showed that the addition of another cytokinin, namely $\mathrm{BAP}$, to the culture medium for most thyme species was required. For example, some scientists obtained the maximum number of shoots per explant at the first stage of micropropagation using medium with $0.1-2.0 \mathrm{mg} / \mathrm{l}$ BAP [8-9] or this hormone together with $0.2 \mathrm{mg} / \mathrm{l} \mathrm{NAA}[4]$.

According to the literature sources, some thyme species at the second stage of micropropagation developed well on a hormone-free culture medium [3]. However, addition of growth regulators to the culture medium is required for most species. They significantly increased the efficiency of micropropagation. Thus, some researchers obtained the maximum multiplication index using Kin $(1.5 \mathrm{mg} / \mathrm{l})$ or this hormone together with NAA $(0.2 \mathrm{mg} / \mathrm{l})$ or IAA $(0.5 \mathrm{mg} / \mathrm{l})[4,8-9]$. Becircan Tuba et al. claimed that the best results among three cytokinins (BAP, Kin, TDZ) showed BAP at a rate of $1.0 \mathrm{mg} / 1$ [10]. Nordine Aicha et al. [9] proposed to use MS culture medium supplemented with $0.5 \mathrm{mg} / \mathrm{l} \mathrm{BAP}$ for T. broussonetii multiple shoot formation; MS with $0.4 \mathrm{mg} / \mathrm{l} \mathrm{GA}_{3}$ - for shoots elongation.

In our experiments, it was revealed that at the stage of $T$. vulgaris micropropagation, as well as at the stage of introduction in vitro, cultivation on culture media containing $\mathrm{GA}_{3}$ with BAP or TDZ contributed to the formation of many small shoots at the base of the explants. Unfortunately, such microshoots cannot be grafted. They did not regenerate into microshoots with several nodes during subsequent subcultivations. It should be noted that some shoots formed on these media were hydrated. Consequently, the number of shoots for micropropagation was significantly reduced. Some scientists mentioned the vitrification of shoots during multiplication in vitro [11-13]. This phenomenon was associated with high humidity and excess of sugars and minerals in plants during cultivation in vitro. As a result, physiological, morphological and anatomical changes due to low efficiency of photosynthesis and disruption of the stomatal apparatus were observed.

The maximum multiplication index (12.8) at the second stage of micropropagation of $T$. vulgaris was obtained on MS medium with $1.0 \mathrm{mg} / \mathrm{l} \mathrm{Kin.} \mathrm{The} \mathrm{use} \mathrm{of} \mathrm{this} \mathrm{culture} \mathrm{medium}$ composition made it possible to obtain high indicators of the explant length $(2.8 \mathrm{~cm})$ and the number of nodes (4.6 pcs./explant) and, thus, propagate T. vulgaris using such techniques as microcutting of shoots and induction of adventitious shoot formation. Addition of auxins and $\mathrm{GA}_{3}$ to Kin was reduced multiplication index.

It is known that at the stage of micropropagation on culture media with kinetin, roots can be formed rather rarely. In our studies, at the second stage of clonal micropropagation, root formation in microshoots in addition to multiple shoots was noted. However, the frequency of rhizogenesis and especially the number of formed roots on most culture media containing only cytokinin was low. Therefore, it is advisable to transfer thyme shoots to 
media containing auxins for active root formation. It was revealed that the use of culture media with auxins at the third stage of micropropagation increased the number of roots per explant. The efficiency of culture medium MS with $1.0 \mathrm{mg} / 1 \mathrm{IBA}$ for rooting microshoots was shown. On this medium we obtained the maximum number of roots per explant -7.7 pcs., which length reached $2.6 \mathrm{~cm}$.

Literature data on in vitro rooting of thyme is rather contradictory. In the work of Polish scientists, 7.8 roots/shoot were obtained using $1.0 \mathrm{mg} / \mathrm{l} \mathrm{IBA}$ in the culture medium at the stage of $T$. vulgare rhizogenesis; 2.4 roots/shoot when adding $0.5 \mathrm{mg} / \mathrm{l}$ IBA to the MS medium [14]. In another study, for rooting in vitro, MS medium with $1.0 \mathrm{mg} / 1 \mathrm{NAA}$ was used [15]. In some studies, there are data on the use of 2,4-D for rooting thyme shoots in vitro [16]. A. Nordine et al. performed in vitro induction of thyme rooting on hormone-free $1 / 2$ MS medium [9].

According to the data available in the literature, different substrates for acclimatization thyme plants ex vitro were used. Z. Bakhtiar and colleagues used mixture of peat and perlite (1:1) and obtained $80 \%$ of adapted $T$. persicus plants [8]. In other works, the best results of adaptation of thyme plants were obtained using a mixture of peat and vermiculite in a ratio of 2:1 [9] or 1.5:1 [3]. E. Sargsyan et al. suggested adapting thyme plants after rooting in vitro under hydroponic conditions in volcanic slag (the adaptation frequency was $93.3 \%$ ) [17].

In our studies on the adaptation of microplants, the use of a substrate that consisted only perlite or perlite together with soil reduced the number of shoots (8.1-8.4 pcs.) compared to the use of peat and perlite $(12.7$ pcs.). The use of a substrate consisting of peat and perlite (1:1) contributed to the production of up to $89.5 \%$ of plants with well-developed aerial (aboveground) part $(9.6 \mathrm{~cm}$ and a weight of $2.4 \mathrm{~g})$ and roots $(12.8 \mathrm{~cm}$ and a weight of 0.34 g).

\section{Conclusions}

As a result of the research, the features of the morphogenesis of T. vulgare explants in vitro were revealed depending on the composition of growth regulators in the culture medium at the main stages of clonal micropropagation. The best culture medium (MS with $1.0 \mathrm{mg} / \mathrm{l}$ $\mathrm{Kin}$ and $1.0 \mathrm{mg} / \mathrm{l} \mathrm{GA}_{3}$ ) for the introduction of $T$. vulgare explants in vitro was revealed. The maximum multiplication index on the optimal culture medium (MS with $1.0 \mathrm{mg} / \mathrm{l} \mathrm{Kin}$ ) at the second stage of micropropagation was 12.8. For in vitro rooting, it is advisable to cultivate shoots on MS medium with $1.0 \mathrm{mg} / \mathrm{l} \mathrm{IBA}$, on which developed 7.7 roots of $2.6 \mathrm{~cm}$ long. For the successful adaptation of microshoots, it is necessary to use a substrate consisting of peat and perlite (1:1), which allows obtaining a high survival rate of microshoots $(89.5 \%)$ and the maximum plant weight $(2.4 \mathrm{~g})$.

\section{References}

1. Aljabeili H S, Barakat H and Abdel-Rahman H A 2018 Chemical composition, antibacterial and antioxidant activities of Thyme essential oil (Thymus vulgaris) Food and Nutrition Sciences (FNS) 9 433-446

2. Achoub H, Zaiter L, Benayache F, Benayache S, Chalchat J C, Chalard P, Figueredo $\mathrm{G}$ and Akkal S 2019 Chemical composition of the essential oil of aerial parts of Thymus ciliatus (Desf.) Acta Scientifica Naturalis (ASN) 6(2) 62-70

3. Marco-Medina A and Casas J L 2015 In vitro multiplication and essential oil composition of Thymus moroderi Pau ex Martinez, an endemic Spanish plant Plant Cell, Tissue Organ Cult. 120 99-108 
4. Nordine A and Meskaoui A 2014 Rapid in vitro regeneration and clonal multiplication of Thymus bleicherianus Pomel, a rare and threatened medicinal and aromatic plant in Morocco Med. Aromat Plants 3(1) 145

5. Tevfik A Sh, Yegorova N A and Zagorskaya M S 2018 Peculiarities of Thymus vulgaris L. explants morphogenesis at the first stage of clonal micropropagation Taurida Herald of the Agrarian Sciences 2(14) 118-127

6. Tevfik A Sh and Yegorova N A 2019 Influence of cultivation conditions and culture medium gormonal composition on the micropropagation Thymus vulgaris L. in vitro Taurida Herald of the Agrarian Sciences 1(17) 93-102

7. El Ansari Z N, El Mihyaoui A, Boussaoudi I, Benkaddour R, Hamdoun O, Tahiri H, Badoc A, El Oualkadi A and Lamarti A 2019 Effect of macronutrients, cytokinins and auxins, on in vitro organogenesis of Thymus vulgaris L. Am. J. Plant Sci. 10 14821502

8. Bakhtiar Z, Mirjalili M H and Sonboli A 2016 In vitro callus induction and micropropagation of Thymus persicus (Lamiaceae), an endangered medicinal plant Crop Breed Appl Biot 16 48-54

9. Nordine A, Bousta D, Khanchoufi A and Meskaoui A 2013 An efficient and rapid in vitro propagation system of Thymus hyemalis Lange, a wild medicinal and aromatic plant of Mediterranean region Int. J. Pharm. Biosci. Technol. 1(3) 118-129

10. Bekircan T, Yaşar A, Yıldırım S, Sökmen M and Sökmen A 2018 Effect of cytokinins on in vitro multiplication, volatiles composition and rosmarinic acid content of Thymus leucotrichus Hal Biotech. 8180

11. Ziv M Quality of micropropagated plants - vitrification 1991 In Vitro Cell Dev BiolPlant 27(2) 64-69

12. Hazarika B N 2006 Morpho-physiological disorders in in vitro culture of plants Sci Hortic 108(2) 105-120

13. Polivanova O B and Cherednichenko M Yu 2017 Ways of vitrification overcoming of Agastache foeniculum (Pursh) Kuntze (Lamiaceae) in in vitro culture Izvestiya of Timiryazev Agricultural Academy (Izvestiya of TAA) 5 17-28

14. Kulpa D, Wesołowska A and Jadczak P 2018 Micropropagation and composition of essentials oils in garden Thyme (Thymus vulgaris L.) Not. Bot. Horti. Agrobo. 46(2)

15. Mendes M and Romano A 1999 In vitro cloning of Thymus mastichina L. field-grown plants Acta Hort $\mathbf{5 0 2} 303-306$

16. Raed Alcowni, Estra Solyman and Hassan Abu Qauod 2017 Introducing some of threatened Thymus species to in vitro tissue culturing as an approach for their conservation Pak. J. Bot. 49(1) 259-264

17. Sargsyan E, Vardanyan A, Ghalachyan L and Bulgadaryan S 2011 Cultivation of Thymus by in vitro and hydroponics combined method International Journal of Biological, Biomolecular, Agricultural, Food and Biotechnological Engineering 5(8) 426-429 